\title{
The Effect of Natural Light on Changes in Antioxidant Content and Color Parameters of Vine-ripened Tomato (Solanum lycopersicum L.) Fruits
}

\author{
Zoltán Pék ${ }^{1}$, Péter Szuvandzsiev, András Nemenyi, and Lajos Helyes \\ Institute of Horticulture and Technology, Szent István University, Páter K. \\ ut 1., H-2103 Gödöllö, Hungary
}

\author{
Andrea Lugasi \\ National Institute for Food and Nutrition Science, Gyáli ut 3/a, H-1097 \\ Budapest, Hungary
}

Additional index words. tomato, antioxidants, color parameters, vine-ripened fruits

\begin{abstract}
During the vine ripening of tomato fruits (Solanum lycopersicum $\mathrm{L}$.), the change in antioxidant content and color was studied under two different solar exposures. An experiment was carried out in 2008 and 2009 to determine how color evolution, surface temperature, and antioxidant content of tomato fruits were influenced by fruit position and exposure on trellised tomato plants. Trellised rows were oriented so that non-shaded fruits were subjected to full solar irradiation from $0900 \mathrm{HR}$ to $1600 \mathrm{HR}$, whereas shaded fruits were completely shaded during the same time period. A significant difference $(P=$ $0.001)$ between fruit surface temperatures of shaded or non-shaded fruits was observed. The more direct solar irradiation the fruits were exposed to, the higher the fruit surface temperatures increased. At $1400 \mathrm{HR}$, only the average temperature of non-shaded fruits was significantly higher $\left(7.0\right.$ and $9.3{ }^{\circ} \mathrm{C}$ in 2008 and 2009 , respectively) than the air temperature. At the end of the ripening process, color change of non-shaded fruits showed significantly higher CIELab hue compared with shaded fruits. A close negative correlation $\left(R^{2}=0.51\right)$ was detected between the hue color parameters and the cumulative fruit surface-air temperature difference of non-shaded fruits, but in the case of shaded fruits, there was only a weak $\left(R^{2}=0.29\right)$ correlation. Solar exposure had a great effect on the antioxidant content of tomato fruits. A higher fruit surface temperature resulted in significantly less lycopene and more polyphenols and ascorbic acid content in tomato fruits.
\end{abstract}

Tomato (Solanum lycopersicum L.) is one of the most important vegetable food crops of the world (FAOSTAT, 2008). Year-round availability, a high rate of consumption, and significant levels of antioxidants such as ascorbic acid, $\beta$-carotene, $\gamma$-carotene, lutein, lycopene, phytoene, phytofluene, phenolic compounds, and vitamin $\mathrm{E}$ increase its health benefits (Abushita et al., 2000; Dumas et al., 2003). Ecological conditions have a substantial effect on fruit components and yield of tomato (Helyes et al., 2008). The ripening process of tomato fruits is well characterized by the color evolution of the fruit surface (Hertog et al., 2007). During the ripening process, chlorophyll breaks down and carotenoids, mostly lycopene, accumulate (Brandt et al., 2006).

Lycopene, which is one of the most important antioxidant fruit components of tomato, has been widely investigated around the world (Dumas et al., 2003). The synthesis of lycopene can easily be detected by the non-destructive

Received for publication 6 Dec. 2010. Accepted for publication 18 Jan. 2011.

This study was partially funded by TECH-09-A32009-0230, USOK2009 project.

${ }^{1}$ To whom reprint requests should be addressed; e-mail helyes.lajos@mkk.szie.hu. method of color measurement of the fruit surface, which is affected by ecological and varietal factors (Pék et al., 2010). Direct solar irradiance causes exposed fruits to overheat and reach temperatures $+10{ }^{\circ} \mathrm{C}$ higher than the shaded fruits, which in turn results in the degradation of lycopene (Helyes et al., 2007). The hue parameter, the most usable color index of the CIELab color system, is closely correlated to the lycopene content of tomato fruits (Hertog et al., 2007). Above $+30{ }^{\circ} \mathrm{C}$ air temperature, the synthesis of lycopene is greatly retarded. Riga et al. (2008) found significant correlations between parameters of tomato quality (antioxidant properties) and daily cumulative temperature and cumulative photosynthetically active radiation $(P A R)$ for a period of $45 \mathrm{~d}$ before harvest in greenhouse experiments.

Combined seasonal and varietal effect on dry weight and ${ }^{\circ}$ Brix was concluded by Anza et al. (2006), whereas when they studied greenhouse plants, they did not measure foliage or fruit surface temperature. Air temperature had a strong positive effect on leaf surface temperature. Deficit-irrigated tomato plants could not transpire sufficient water to cool leaves below air temperature and it causes stress, although regularly irrigated plants did not heat over air temperature owing to enough soil water content (Böcs et al., 2009). In the tomato fruit, exposure to light promotes ascorbic acid accumulation. Lower ascorbic acid levels were found in greenhouse-grown tomatoes than in those grown outdoors (Lopez-Andreau et al. 1986). Despite this, the concentration of total ascorbate increased significantly by higher temperature in greenhouse conditions (Rosales et al., 2006).

Tomatoes grown under high light exposure also had greater soluble phenolic content than under low light conditions (Wilkens et al., 1996). Toor and Savage (2005) detected significantly higher levels of total phenolics (both lipophilic and hydrophilic) in the skin tissues of tomato fruits.

The aim of the present study was to examine the effect of different solar exposure on the evolution of color and the determination of tomato fruit components during the ripening process.

\section{Materials and Methods}

A round, indeterminate growth-type tomato cultivar, Lemance $F_{1}$ (with an average fruit weight of 110 to $130 \mathrm{~g}$ ), was grown for the present study on a supporting trellis system in the open field in years 2008 and 2009, respectively.

In both years, plants were planted out in the field on the 10 May supported by a high wire system. Plants were planted in twin rows oriented northwest to southeast with a plant density of 3.6 plants $/ \mathrm{m}^{2}$. Individual plants were properly pruned to one stem and irrigated with a standard nutrient solution by means of a drip irrigation system. A highly absorptive black polyethylene mulch cover was placed on the soil surface. The experimental design was a randomized block with four replications with four fruits in each replication. The plants were exposed to direct solar irradiation and either the fruits were non-shaded, receiving full irradiation $(\mathrm{FI})$, or were shaded by the foliage $(\mathrm{S})$ during the course of the day. Each selected FI fruit had no shading from at least $0900 \mathrm{HR}$ to $1600 \mathrm{HR}$, whereas shaded fruits (S) were totally shaded by the foliage.

Sample fruits nearest to the peduncle in the third cluster from 16 plants in west (nonshaded in the afternoon) and east (control, shaded by foliage) sides of twin rows were harvested from each plant for the investigation of fruit components and color evolution.

Color measurements were performed by a Sheen Micromatch Plus tristimulus colorimeter (Sheen Instruments Ltd., Kingston-UponThames, U.K.) at three points in the equatorial region of the tomatoes applying the CIELab color system. The $\mathrm{L}^{*}, \mathrm{a}^{*}, \mathrm{~b}^{*}$ values, received directly, were used to calculate the hue:

$$
\begin{aligned}
& \operatorname{Hue}\left(^{\circ}\right)=\tan ^{-1}\left(\mathrm{~b}^{*} \mathrm{a}^{*-1}\right), \text { if } \mathrm{a}^{*}>0 \text { and } \\
& \operatorname{Hue}\left(^{\circ}\right)=180+\tan ^{-1}\left(\mathrm{~b}^{*} \mathrm{a}^{*-1}\right), \text { if } \mathrm{a}^{*}<0 .
\end{aligned}
$$

The fruit surface temperature was measured by a Raytek MX TD4 type IR remote thermometer (Raytek Corporation, Santa Cruz, CA).

Fruit components were determined from four fruits in four replicates. The ${ }^{\circ}$ Brix value was measured using a refractometer (AST 1230, Tokyo, Japan). The organic acid content 
expressed as $\mathrm{g} \cdot \mathrm{kg}^{-1}$ citric acid in fresh weight was determined according to the AOAC method 932.12 (AOAC, 1990). The carbohydrate content was measured after an acidic hydrolysis with $\mathrm{HCl}$ at $65{ }^{\circ} \mathrm{C}$ for $5 \mathrm{~min}$ following the Schoorl-Regenbogen method (Commission Directive, 1979). The total polyphenols were analyzed with the Folin-Denis method according to the AOAC official protocol 952.03 (AOAC, 1990). The analysis of ascorbic acid content was performed chromatographically using high-performance liquid chromatography (Dong and Pace, 1996) with a Perkin Elmer HPLC ultraviolet/VIS (Perkin Elmer Co., Norwalk, CT). Lycopene was extracted from the tomato juice with a mixture of n-hexane, methanol, and acetone (2:1:1) containing BHT. Optical density of the hexane extract was measured at $502 \mathrm{~nm}$ by a Perkin Elmer Lambda 3B ultraviolet Spectrophotometer (Perkin Elmer Co.) (Sadler et al., 1990). Lycopene concentrations were calculated by applying the molecular extinction coefficient of 158500 (Merck \& Co., 1989).

The results were expressed as the average plus/minus significant differences at $P=0.05$. The statistical analysis was carried out by the Student's $t$ test, and the statistical analysis was performed using Statistica 9 software (Statsoft Inc., Tulsa, OK).

\section{Results and Discussion}

There was a significant difference $(P=$ 0.001 ) between non-shaded (FI) and shaded (S) tomato fruit surface temperatures. The more direct solar irradiation the fruits were exposed to, the higher their surface temperatures increased. Only the average temperature of nonshaded fruits was significantly higher (7.0 and $9.3^{\circ} \mathrm{C}$ in 2008 and 2009, respectively) than the air temperature at $1400 \mathrm{HR}$ (data not shown).

CIELab hue parameter is the most commonly used parameter to indicate the development of red coloration during the ripening of tomato fruits. Figure 1 shows the evolution of the hue value of tomato fruits during the ripening process. The hue value of tomato fruits exposed to direct solar irradiation (FI) was significantly higher (less red color) than fruits shaded by the canopy. However, the evolution of the red color in tomato fruits was more rapid under exposure to full solar irradiance. Color change of tomato fruits shaded by the canopy was different, because lycopene, the main source of the red color of tomato fruits, is not synthesized above $+30{ }^{\circ} \mathrm{C}$. In this high temperature range, only $\beta$-carotene is produced, which has a ceiling temperature of $38^{\circ} \mathrm{C}$ (Brandt et al., 2006). Temperature during the ripening process greatly influences the ripening of tomato fruits. Hertog et al. (2007) reported similar temperature effects while studying color changes of detached tomato fruits at different constant temperatures.

Ascorbic acid, carbohydrate, lycopene, organic acid, phenolic compound, and soluble solid ( ${ }^{\circ}$ Brix) content were also evaluated (Table 1). There were significant differences in carbohydrates, organic acids, phenolic compounds, and soluble solids between the two

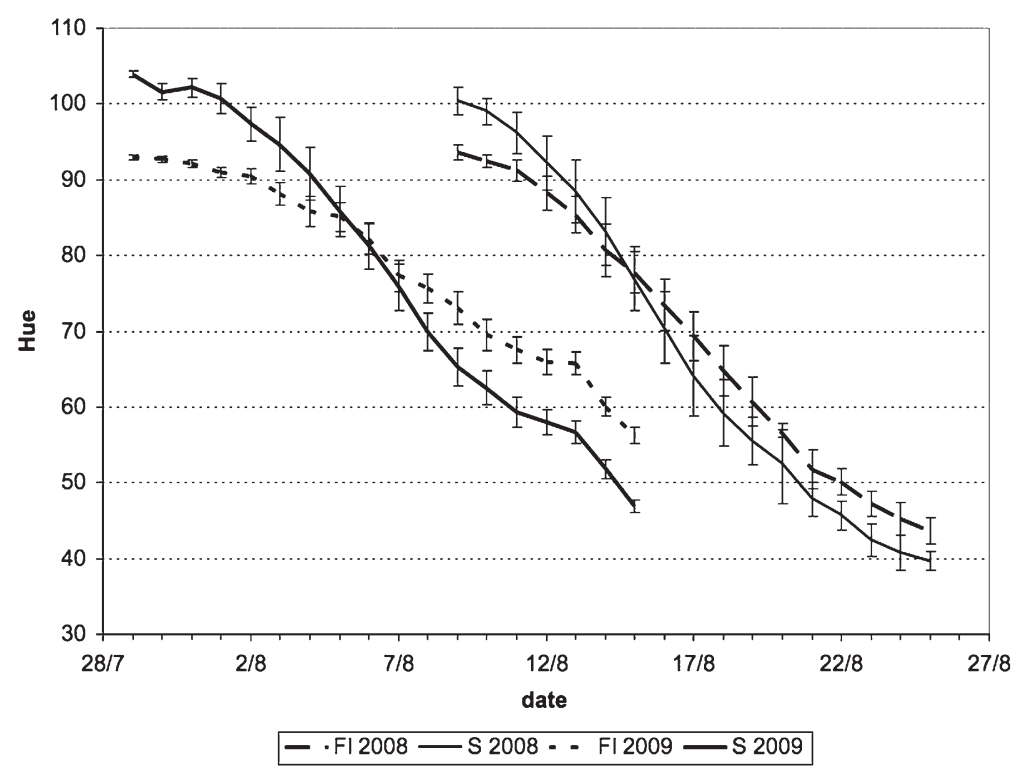

Fig. 1. Evolution of hue color parameters of shaded (S) and non-shaded (FI) tomato fruits during the ripening process in 2008 and 2009. Vertical bars represent significant differences at $P=0.05$ (cv. Lemance $\mathrm{F}_{1} ; \mathrm{n}=16$ ).

Table 1. Components of non-shaded (FI) and shaded (S) tomato fruits at the end of the ripening process in 2008 and 2009 (cv. Lemance $\mathrm{F}_{1} ; \mathrm{n}=4 ; \pm \mathrm{sD}$ ).

\begin{tabular}{|c|c|c|c|c|c|c|c|}
\hline & & $\begin{array}{c}\text { Soluble } \\
\text { solids }\left({ }^{\circ} \text { Brix }\right)\end{array}$ & $\begin{array}{c}\text { Carbohydrates } \\
(\%)\end{array}$ & $\begin{array}{c}\text { Organic } \\
\text { acids }(\%)\end{array}$ & $\begin{array}{l}\text { Ascorbic acid } \\
(\mathrm{mg} / 100 \mathrm{~g})\end{array}$ & $\begin{array}{c}\text { Phenolic } \\
\text { compounds }(\mathrm{mg} / 100 \mathrm{~g})\end{array}$ & $\begin{array}{l}\text { Lycopene } \\
(\mathrm{mg} / 100 \mathrm{~g})\end{array}$ \\
\hline \multirow[t]{2}{*}{$\overline{2008}$} & $\mathrm{~S}$ & $6.0 \pm 0.56^{\mathrm{az}}$ & $3.5 \pm 0.46^{\mathrm{a}}$ & $3.8 \pm 0.23^{\mathrm{a}}$ & & $35.7 \pm 3.74^{\mathrm{a}}$ & $6.5 \pm 0.98^{2}$ \\
\hline & FI & $6.4 \pm 0.47^{\mathrm{a}}$ & $3.8 \pm 0.26^{\mathrm{a}}$ & $3.4 \pm 0.23^{\mathrm{a}}$ & & $38.6 \pm 2.07^{\mathrm{a}}$ & $4.7 \pm 0.84$ \\
\hline \multirow[t]{2}{*}{2009} & $\mathrm{~S}$ & $4.8 \pm 0.10^{\mathrm{b}}$ & $2.2 \pm 0.40^{\mathrm{b}}$ & $3.2 \pm 0.04^{b}$ & $20.0 \pm 2.23^{\mathrm{a}}$ & $37.6 \pm 1.56^{\mathrm{a}}$ & $5.6 \pm 0.59^{2}$ \\
\hline & FI & $5.0 \pm 0.11^{\mathrm{b}}$ & $2.7 \pm 0.08^{c}$ & $3.0 \pm 0.15^{\mathrm{c}}$ & $26.8 \pm 3.63^{\mathrm{b}}$ & $47.2 \pm 3.00^{\mathrm{b}}$ & $4.4 \pm 0.42^{\mathrm{b}}$ \\
\hline
\end{tabular}

${ }^{\mathrm{Z}}$ Data in the same column bearing the same superscript letter are not significant at $P=0.05$.

seasons but none between $\mathrm{S}$ and FI fruits in 2008. There was a significant difference between S and FI fruits in carbohydrate, organic acid, ascorbic acid, phenolic compound, and lycopene content in 2009. Exposure to direct solar irradiation increased the carbohydrate (19\%), ascorbic acid (25\%), and phenolic compound $(20 \%)$ and decreased organic acid $(6 \%)$ and lycopene $(21 \%)$ content of tomato fruits, because the 2009 weather conditions produced significantly higher air temperatures and solar radiation than in the previous year.

Lycopene content of FI fruits was significantly lower (28 and $21 \%$, respectively) in both years, because direct solar irradiation caused overheating of the fruit surface above the maximum temperature $+30{ }^{\circ} \mathrm{C}$ for lycopene biosynthesis, which resulted in the significant delay of red pigmentation, whereas the surface temperature of S fruits was analogous with air temperature. This temperaturedependent effect is demonstrated in Figure 2. Linear regression functions of hue color parameter and cumulative fruit surface-air temperature difference of differently exposed tomato fruits show a stronger negative correlation in FI $(R=-0.72)$ than $\mathrm{S}(R=$ $-0.53)$ tomato fruits. This agrees with the findings of Helyes et al. (2007), who found that tomato fruit surface temperature has a major role in the lycopene biosynthesis of ripening tomato fruits.
The mechanism of the on-vine tomato fruit ripening process seems to be different in relation to canopy shading of fruits. Tomato fruit surface temperature behavior, particularly during the diurnal phase, when the thermal effect of solar forcing cannot be effectively described by air temperature. We have measured indirectly the heating effect on fruits of direct sunlight only and not the PAR on the canopy as described by Anza et al. (2006) and Riga et al. (2008). They measured the ambient air temperature and incident $P A R$ and concluded similarly that fruit quality is more dependent on temperature than $P A R$.

The 2 different years resulted strong seasonal effect on ${ }^{\circ}$ Brix as Anza et al. (2006) concluded. We also did not establish a significant difference between FI and $\mathrm{S}$ fruits in ${ }^{\circ}$ Brix, only between years; meanwhile, cumulative yield or average fruit weight was not significantly different at all.

Results of lycopene content agreed with the findings of previous studies on tomato fruits, in which $32^{\circ} \mathrm{C}$ and higher temperatures induced the degradation of lycopene (Dumas et al., 2003; Rosales et al., 2006). Lycopene in the mesocarpic and endocarpic fractions were far lower than those present in the exocarp in fresh fruit tomatoes (Toor and Savage, 2005), so overheating of fruit surface temperature by intense solar radiation could cause inhibition of lycopene synthesis and discoloration 


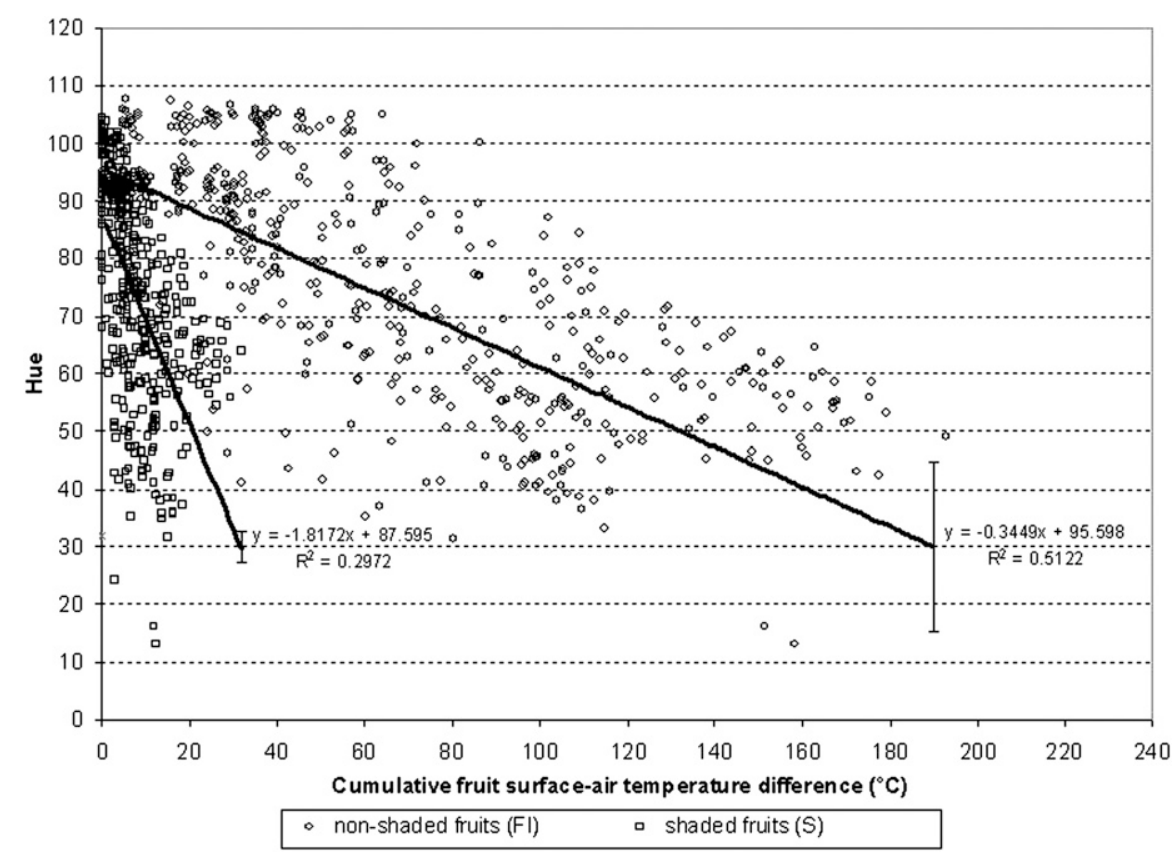

Fig. 2. Correlation between hue color parameter and cumulative fruit surface-air temperature difference of shaded (S) and non-shaded (FI) tomato fruits with linear regression functions in 2008 and 2009 Vertical bars represent SE of regression (cv. Lemance $\mathrm{F} 1 ; \mathrm{n}=560$ ).

known as sunscald (Adegoroye and Joliffe, 1983).

Ascorbic acid and phenolic compounds show opposite results; FI fruits consisted of higher amounts of these compounds, agreeing with Rosales et al. (2006), and improbable distribution is consistent.

Our experiment proved that direct solar irradiation has a major effect on the main tomato fruit components, especially on antioxidants. Meanwhile, separating of overheating and radiation effect of direct sunlight require further experiment.

\section{Literature Cited}

Abushita, A.A., H.G. Daood, and P.A. Biacs. 2000. Change in carotenoids and antioxidant vitamins in tomato as a function of varietal and technological factors. J. Agr. Food Chem. 6:2075-2081.
Dong, M.W. and J.L. Pace. 1996. A rapid HPLC method for multivitamin analysis. LC GC 14: 794-803.

Dumas, Y., M. Dadomo, G. Di Lucca, and P. Grolier. 2003. Effects of environmental factors and agricultural techniques on antioxidant content of tomatoes. J. Sci. Food Agr. 83:369382.

FAOSTAT. 2008. Production crops. FAOSTAT Agricultural production database. 1 Dec. 2010. $<\mathrm{http}: / /$ faostat.fao.org $>$.

Helyes, L., A. Lugasi, and Z. Pék. 2007. Effect of natural light on surface temperature and lycopene content of vine ripened tomato fruit. Can. J. Plant Sci. 87:927-929.

Helyes, L., Z. Pék, and A. Lugasi. 2008. Function of the variety technological traits and growing conditions on fruit components of tomato [Lycopersicon lycopersicum (L) Karsten]. Acta Aliment. 37:427-436.

Hertog, M.L.A.T.M., J. Lammertyn, N. Scheerlinck, and B.M. Nicolai. 2007. The impact of biological variation on postharvest behaviour: The case of dynamic temperature conditions. Postharvest Biol. Technol. 43:183-192.

Lopez-Andreu, F.J., A. Lamela, R.M. Esteban, and J.G. Collado. 1986. Evolution of quality parameters in the maturation stage of tomato fruit. Acta Hort. 191:387-394.

Merck \& Co. 1989. Merck index. 11th Ed. Merck \& Co., Inc., Rahway, NJ.

Pék, Z., L. Helyes, and A. Lugasi. 2010. Color changes and antioxidant content of vine and post-harvest ripened tomato fruits. HortScience 45:466-468.

Riga, P., M. Anza, and C. Garbisu. 2008. Tomato quality is more dependent on temperature than on photosynthetically active radiation. J. Sci. Food Agr. 88:158-166.

Rosales, M.A., J.M. Ruiz, J. Hernández, T. Soriano, N. Castilla, and L. Romero. 2006. Antioxidant content and ascorbate metabolism in cherry tomato exocarp in relation to temperature and solar radiation. J. Sci. Food Agr. 86:1545-1551.

Sadler, G., J. Davies, and D. Dezman. 1990. Rapid extraction of lycopene and $\beta$-carotene from reconstituted tomato paste and pink grapefruit homogenates. J. Food Sci. 55:1460-1461

Toor, R.K. and G.P. Savage. 2005. Antioxidant activity in different fractions of tomatoes. Food Res. Intl. 38:487-494.

Wilkens, R.T., J.M. Spoerke, and N.E. Stamp. 1996. Differential responses of growth and two soluble phenolics of tomato to resource availability. Ecology 77:247-258. 